\title{
Meeting Report: the 18th Annual Biosemiotics Gathering at the University of California, Berkeley
}

\author{
Yogi Hale Hendlin ${ }^{1,2}$ (D)
}

Received: 27 February 2019 / Accepted: 28 April 2019/Published online: 03 May 2019

(C) Springer Nature B.V. 2019

Keywords Biosemiotics · Meeting $\cdot$ Gatherings in biosemiotics $\cdot$ Conferences

June 17-20, 2018, from dozens of countries, biosemioticians converged in the International House auditorium on the University of California, Berkeley campus to discuss the state of the art of the discipline at the Eighteenth Annual Biosemiotics Gathering. This Gathering was organized by Terrence Deacon and myself, under the auspices of the International Society for Biosemiotic Studies. The syncretic gathering, like the discipline itself, brought together scholars in natural science, social science, and the humanities, to further develop, like signs themselves esse in futuro, what Danish chemist and $u r$-biosemiotian Jesper Hoffmeyer calls "the life of signs, and the signs of life." As promised, this Gathering not only examined the hermeneutics of biological communication, serving also as an interpretive companion to the findings of the Extended Evolutionary Synthesis, but this year pushed biosemiotics once again to address those primordial questions What is life? and Is semiosis co-extensive with life?

Before referring to the specific themes of the Eighteenth Gathering, for those not yet acquainted with these goings-on, it is worth reflecting on the unique structure of them. Rather than a standard showcase conference, as mutualistic scholars the Biosemiotics Gatherings programmatically are fiercely egalitarian. We have no keynotes (even though we have papers given by many of the leaders in our and other fields), no parallel breakout sessions, no hierarchy - it's a thoroughly rhizomatic organization. Because of this, bachelors students and decorated professors are allotted the same amount of time on stage. The Gathering is held as one big plenary, so that after the first couple days, participants begin to connect disparate corners of the discipline across presentations, so that a sort of dynamic cohesive unity takes place, akin to Schopenhauer's parable of the

Yogi Hale Hendlin

Hendlin@esphil.eur.nl

1 Erasmus School of Philosophy, Core Faculty, Dynamics of Inclusive Prosperity Initiative, Erasmus University Rotterdam, Rotterdam, Netherlands

2 Environmental Health Initiative, University of California, San Francisco, 530 Parnassus Ave, \#366, San Francisco, CA 94143, USA 
hedgehogs that come together for (disciplinary) warmth but also must keep a healthy distance to avoid each other's (sub-discipline specific) quills.

This year, the Gathering included two special panels: one reflecting on the successes, methodologies, and challenges of teaching biosemiotics in the university setting and beyond, and one discussing the biosemiotics of food vis-à-vis the human animal. Both brought in new and familiar scholars to discuss these practically-oriented questions in rich conversation. We also incorporated a few teleconference presentations from scholars such as Jesper Hoffmeyer and Eduardo Kohn, who were unable to attend in person, conserving their ecological footprint but still contributing. As the entire conference was livestreamed, we had other biosemioticians around the globe listening in on many of the presentations. Thanks to the CounterBalance Foundation, we were able to record most of the presentations, which are available on the biosemiotics organizational website.

One of the evenings, many biosemioticians also enjoyed watching John Feldman's film on the life and work of Lynn Margulis, Symbiotic Earth. The film encapsulates the wonder for nature, and the merits of breaking convention with reductive models in biology, an enterprise that biosemioticians hold dear.

This year, thanks in part to a more inclusive program with poster sessions and geographic proximity, we had an unprecedented number of presenters from Latin America, especially Mexico. Many of these presentations focused on the connections between indigenous cultural semiotics as grounded in biosemiotic and ecosemiotic processes.

With Terrence Deacon as organizer, many kindred thinkers who are part of his informal study group colloquially known as "the Pirates" contributed papers on topics related to unresolved questions sparked by his Incomplete Nature and The Symbolic Species. Papers on these topics asked about the necessary role of constraints for the emergence of life, how autocatalysis can lead to dynamical "living" systems (however sporadic or periodic), and how different "levels" of semiosis build upon one another. One of the reoccurring themes of the Gathering, in addition to rich Peircean analysis, dealt with question of meaning versus information. This bridge between information studies and biosemiotics stressed the semiotic point that information does not necessarily exist independently or have meaning on its own, but gains this through an interpreter. Because of the vast diversity of "interpreters," from a particular human to, say, a specific species of fire ant, phenomena show up differently to different organisms, and thus only through interpretation by a living being do events crystalize into meanings and significance. This question of how relationships occur between beings, things, and the signs that different species perceive, are acted upon and thus further influence the world, generating a thoroughly non-anthropocentric biology and epistemology. While such understandings may be axiomatic to biosemioticians, the necessary application of these insights to information science and studies became clear.

In a similar friendly spirit that Richard Feynman worked to bring intercultural exchanges between the US and the USSR during the Cold War through science and music, the 2019 Biosemiotic Gathering will be held in Moscow, Russia. More information about the International Society for Biosemiotic Studies can be found at the website www.biosemiotics.org.

Publisher's Note Springer Nature remains neutral with regard to jurisdictional claims in published maps and institutional affiliations. 